\title{
One bottle too many? Method of testing determines the detection of overshadowing and retention of taste aversions
}

\author{
W. ROBERT BATSELL, JR., and MICHAEL R. BEST \\ Southern Methodist University, Dallas, Texas
}

\begin{abstract}
A two-bottle testing method generally is regarded as a more sensitive measure of taste aversions than a one-bottle test. The current research compared the sensitivity of one-bottle and twobottle tests in the detection of taste aversions. Specifically, the experiments were designed to detect both overshadowing (single- vs. compound-element conditioning) and retention interval ( 5 days vs. 1 day) effects. The groups tested with the one-bottle method evidenced both significant overshadowing and stronger aversions at 5-day retention intervals. On the other hand, the differences on these measures were not significant with the two-bottle tests. It is suggested that the efficacy of the two-bottle test be re-evaluated since it may obscure between-group differences in aversion strength.
\end{abstract}

It has been reported that two-bottle tests are more sensitive than single-bottle tests in the measurement of taste aversion (e.g., Dragoin, McCleary, \& McCleary, 1971; Elkins, 1973; Grote \& Brown, 1971; Klein, Domato, Hallstead, Stephens, \& Mikulka, 1975; Riley \& Mastropaolo, 1989). For instance, Grote and Brown (1971) compared three dose levels (none, weak, and strong) of an unconditioned stimulus in both young (21-day-old) and adult (70-day-old) rats. The rats' saccharin aversions were assessed by using either a one-bottle or a two-bottle method. Although both methods were effective in demonstrating effects due to age and dosage, only preference scores derived from the two-bottle testing method were significant. Similarly, Dragoin et al. (1971) demonstrated that a two-bottle test was more sensitive in detecting the presence of an aversion when an illness group was compared with a no-illness control. These authors concluded that "the preference-drinking method is a much more sensitive measure of learned aversions than is the forceddrinking method"' (p. 310). Also, investigators have shown that this preference method is a very sensitive measure for studying the acquisition of taste aversions (Klein et al., 1975), discriminations between liquids (e.g., Harriman, Nance, \& Milner, 1968; Strom, Lingenfelter, \& Brody, 1970), aversions formed with the use of long intervals between the conditioned stimulus and the unconditioned stimulus (e.g., Riley \& Mastropaolo, 1989;

The present research was supported by NSF Grant BSN-8809508. The authors would like to thank Howard Hurd, Chris Jones, and Kim Novak for their help in this project. Also, we thank Atomergic Chemetals Corporation, 91 Carolyn Boulevard, Farmingdale, NY 11735-1527 for supplying the denatonium saccharide. Address correspondence to R. Batsell, Department of Psychology, Southern Methodist University, Dallas, TX 75275.
Rozin, 1969), and changes during extinction (e.g., Elkins, 1973). As such, outcomes from two-bottle tests have been regarded as being more accurate than those from onebottle tests.

Although these advantages of the two-bottle testing method are well established, a number of factors hamper the interpretation of such studies. For instance, in many of them (Dragoin et al., 1971; Elkins, 1973), the onebottle and two-bottle groups differed in exposure to the aversive fluid. In some cases (Dragoin et al., 1971), the one-bottle groups were given only a short (i.e., 10-min) testing period, whereas the two-bottle groups had a much longer exposure to the fluids (i.e., $12 \mathrm{~h}$ ). More importantly, little attention has been paid to the possibility that the two-bottle testing method may be an ineffective measure when groups that possess aversions of differential strength are compared. For example, with the two-bottle method, if comparisons are made only between aversively conditioned animals and no-illness or weakly conditioned controls, it is reasonable to expect a pronounced difference between these groups. The group possessing the weak (or no) aversion should consume larger amounts of the aversive fluid than the group with the stronger aversion. However, if all of the animals have been aversively conditioned, and differences in aversion strength are expected between the two groups, the two-bottle method may be less sensitive. With the two-bottle method, when given the choice between consuming the aversively conditioned taste or a "safe" liquid, all rats have the opportunity to avoid drinking exclusively from the bottle containing the aversive flavor. In addition, this procedure should contribute to a slow rate of extinction for all groups. As a result, group differences in aversion strength might not be detected. On the other hand, with the one-bottle method, subjects must drink "in the presence of their aversion" and rats with stronger aversions should drink 
less than those with weaker aversions. As such, differential aversions might be more readily observed.

The ability to detect differences in aversion strength is important, because much of the research in taste aversion learning over the last decade has centered on the differences between single-element and compound-element conditioning (for an extensive review, see LoLordo \& Droungas, 1989). Typically, when a strong taste is conditioned in compound with an odor or a weak taste, these stimuli are differentially conditioned in comparison with single-element controls. Specifically, the aversion to the strong taste is decreased in comparison with the aversion of the taste-only control. This effect is commonly referred to as overshadowing (see, e.g., Bouton \& Whiting, 1982; Bowman, Batsell, \& Best, 1992; Davis, Best, \& Grover, 1988; Westbrook, Homewood, Horn, \& Clarke, 1983). In the detection of overshadowing, comparisons are made between pairs of groups that potentially possess strong aversions. Thus, the ability to measure differential aversions is crucial to an understanding of these phenomena.

Furthermore, recent work in the study of compound conditioning has focused on differences in aversion strength at various retention intervals (Batsell \& Best, 1992a, 1992b; Kraemer, Lariviere, \& Spear, 1988; Miller, Jagielo, \& Spear, 1990). For example, Batsell and Best (1992b) demonstrated that both single-taste and overshadowed-taste aversions were significantly weaker at a short retention interval (i.e., 1 day) than at a longer one (i.e., 21 days). The presence of overshadowing or retention interval effects is dependent on a measurement technique that is well suited to detecting differential aversions. In these cases, the twobottle method may be less sensitive, because it favors slow extinction. As adumbrated earlier, since the two-bottle method allows for a rat to avoid drinking the aversive fluid, that aversion will take longer to become extinguished than it will if a one-bottle test is used (Elkins, 1973).

In the present experiment, a two-bottle testing method was directly compared with a one-bottle method to evaluate the ability of each to detect differences between groups possessing relatively strong aversions. In particular, we investigated the detection of overshadowing and retention interval differences. The design mirrored our previous procedures (Batsell \& Best, 1992b; see Experiments 2 and 6 ). The retention intervals were set at 1 and 5 days, and at each of these intervals, the animals were conditioned to either denatonium or a mixture of denatonium and saccharin. These specific fluids were selected because prior work has demonstrated that conditioning with denatonium in compound with saccharin produces overshadowing of the denatonium (Davis et al., 1988).

\section{METHOD}

\section{Subjects}

Seventy-seven male albino Holtzman rats were subjects in this experiment. The rats were born and raised in the Southern Methodist University vivarium, and their weights ranged between 300 and $400 \mathrm{~g}$ at conditioning. The vivarium was on a 12:12-h light:dark cycle, with the light cycle beginning at $0600 \mathrm{~h}$. All the rats were singly housed in standard Wahmann hanging cages, and all the manipulations (conditioning and testing) occurred at $1200 \mathrm{~h}$ in these familiar cages. Also, the rats had free access to food during all phases of the experiment. After 2 weeks of familiarization with the vivarium, all the animals were placed on a water deprivation schedule. They were given access to $40 \mathrm{ml}$ of water at room temperature for $20 \mathrm{~min}$ each day at $1200 \mathrm{~h}$. All fluids were presented in $50-\mathrm{ml}$ calibrated polypropylene drinking tubes, and intakes were recorded to the nearest $0.1 \mathrm{ml}$. The animals remained on this water deprivation schedule throughout the duration of the experiment (approximately 3 weeks). The animals' mean water intakes for the 8 days prior to conditioning were used to match them into eight groups, with four of the groups at each testing method. These eight groups were equally divided according to compound conditioning and retention interval manipulations.

\section{Procedure}

Four groups were designated as one-bottle (1B) test groups, and the other four were the two-bottle (2B) test groups. These groups were treated in an identical manner, apart from the testing method. The four groups in each testing method were divided according to retention interval ( 5 days vs. 1 day) and conditioning liquid (singleelement denatonium, D, vs. compound-element saccharin + denatonium, $S+D$ ). Thus, the four groups tested with the one-bottle method were 5D-1B $(n=9)$, which was conditioned to denatonium 5 days before testing; $5 S+D-1 B(n=9)$, which was conditioned to saccharin + denatonium 5 days before testing; 1D-1B $(n=10)$, which was conditioned to denatonium 1 day before testing; and $1 \mathrm{~S}+\mathrm{D}-1 \mathrm{~B}(n=10)$, which was conditioned to saccharin + denatonium 1 day before testing. The other four groups, the twobottle groups, were treated similarly. These groups were designated as 5D-2B; 5S+D-2B; 1D-2B; and 1S+D-2B. All of the two-bottle groups had 10 members, except for Group $5 S+D-2 B$, which had 9 members.

For conditioning, rats were presented with either the singleelement denatonium saccharide (a $0.01 \%$ solution: 1 part denatonium to 10,000 parts water) or a compound mixture of denatonium and a $0.15 \%$ sodium saccharin solution. During conditioning, the subjects were given $8 \mathrm{ml}$ of their designated solution for $10 \mathrm{~min}$. Fifteen minutes after the drinking tubes were removed, the animals were given an intraperitoneal injection of a $0.15 \mathrm{M}$ lithium chloride solution $(12 \mathrm{mg} / \mathrm{kg}$ of body weight). No replacement fluids were given following conditioning. To equate fluid intakes at the 1-day conditioning interval, all 5-day groups were given access to $8 \mathrm{ml}$ of water.

During testing for the one-bottle groups, tubes containing $30 \mathrm{ml}$ of denatonium were attached to the cages at $1200 \mathrm{~h}$. After $20 \mathrm{~min}$, these tubes were removed. At the same time, the two-bottle animals were also tested. Each animal in this group was given a bottle that contained $30 \mathrm{ml}$ of denatonium and a second tube that contained $30 \mathrm{ml}$ of water. The position of these tubes on the cage was alternated between sides of the cage over test days. Since the experimenters were blind to subject assignment, these variations were random across the two-bottle groups. All intakes were recorded to the nearest $0.1 \mathrm{ml}$. This procedure was repeated over 3 consecutive days. Finally, to minimize any differences that might be due to unequal hydration, all the animals received their daily water maintenance $5 \mathrm{~h}$ after testing on each of the test days.

\section{Data Analysis}

The intakes of the one-bottle and two-bottle groups were analyzed separately. A $2 \times 2 \times 3$ mixed analysis of variance (ANOVA) was used, with interval ( 5 days vs. 1 day), liquid (denatonium vs. saccharin + denatonium), and trials as the factors. Planned comparison $t$ tests were used to assess between-group differences resulting from retention interval or conditioning fluid manipulations. The significance level was set at .05. 


\section{RESULTS}

\section{Group Assignment and Conditioning}

All the rats were matched into eight groups according to their water intakes for the week preceding 5-day conditioning. The mean group intakes ranged from 21.2 to $21.8 \mathrm{ml}$.

Since any differences between the one-bottle and the two-bottle groups would not be evident until testing, the fluid intakes during conditioning were pooled for analysis. During conditioning, the denatonium groups drank more fluid than did the saccharin + denatonium groups: $5 \mathrm{D}=6.5 \mathrm{ml} ; 1 \mathrm{D}=7.68 \mathrm{ml} ; 5 \mathrm{~S}+\mathrm{D}=2.8 \mathrm{ml}$; and $1 \mathrm{~S}+\mathrm{D}=2.15 \mathrm{ml}$. The ANOVA of the conditioning intakes revealed a significant liquid effect $[F(1,74)=$ $370.6]$ and a significant interaction $[F(1,74)=14.5]$; the interval effect was not significant $[F(1,74)=1.4] .{ }^{1}$

\section{One-Bottle Groups}

On Test Day 1, Group 1S+D-1B drank the most $(10.3 \mathrm{ml})$, Group 5D-1B drank the least $(2.67 \mathrm{ml})$, and Groups 1D-1B and 5S + D-1B drank comparable amounts (5.81 and $6.3 \mathrm{ml}$, respectively). A similar trend in responding was observed on Test Day 2: Group 5D-1B = $7.2 \mathrm{ml}$, Group 5S +D-1B $=16.1 \mathrm{ml}$, Group 1D-1B = $17.7 \mathrm{ml}$, and Group $1 \mathrm{~S}+\mathrm{D}-1 \mathrm{~B}=19.9 \mathrm{ml}$. On Test Day 3, Group 5D-1B still drank the least denatonium $(13.2 \mathrm{ml})$, whereas the other three groups drank equal amounts: Group 5S+D-1B $=17.2 \mathrm{ml}$, Group 1D-1B = $16.6 \mathrm{ml}$, and Group $1 \mathrm{~S}+\mathrm{D}-1 \mathrm{~B}=17.6 \mathrm{ml}$.

Figure 1 presents the mean denatonium intakes of the four one-bottle groups averaged over the 3 test days. The ANOVA revealed both significant interval $[F(1,34)=$ $24.7]$ and liquid effects $[F(1,34)=22.6]$, but the inter-

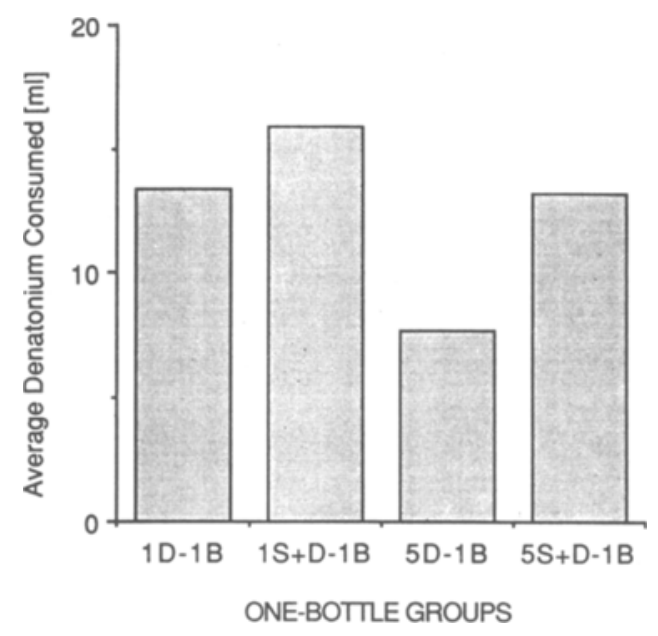

Figure 1. Mean denatonium consumption in milliliters of Groups $1 D-1 B, 1 S+D-1 B, 5 D-1 B$, and $5 S+D-1 B$ averaged over the 3 days of testing. Groups $1 D-1 B$ and $1 S+D-1 B$ were tested 1 day after conditioning whereas Groups $5 \mathrm{D}-1 \mathrm{~B}$ and $5 \mathrm{~S}+\mathrm{D}-1 \mathrm{~B}$ were tested 5 days after conditioning. Groups 1D-1B and 5D-1B were conditioned to denatonium whereas Groups $1 S+D-1 B$ and $5 S+D-1 B$ were conditioned to a saccharin/denatonium mixture.
Table 1

Group Mean Denatonium Consumption (in Milliliters) and Percentage of Denatonium Consumed

\begin{tabular}{|c|c|c|c|c|c|c|c|c|}
\hline \multirow[b]{3}{*}{ Test } & \multicolumn{8}{|c|}{ Group } \\
\hline & \multicolumn{2}{|c|}{$5 D-2 B$} & \multicolumn{2}{|c|}{$5 S+D-2 B$} & \multicolumn{2}{|c|}{ ID-2B } & \multicolumn{2}{|c|}{$1 S+D-2 B$} \\
\hline & Intake & $\%$ & Intake & $\%$ & Intake & $\%$ & Intake & $\%$ \\
\hline 1 & 0.53 & 2.25 & 0.41 & 1.94 & 1.00 & 4.6 & 0.30 & 1.3 \\
\hline 2 & 0.50 & 2.50 & 0.41 & 2.00 & 0.93 & 5.4 & 0.31 & 1.6 \\
\hline 3 & 0.15 & 0.88 & 0.58 & 3.30 & 0.46 & 2.8 & 0.23 & 1.3 \\
\hline
\end{tabular}

action effect was not significant $[F(1,34)=3.1]$. Planned comparisons showed that overshadowing was evident at both the 5-day and the 1-day retention intervals, and that both the single-element and the compound-element groups drank more denatonium at the 1-day retention interval than at the 5-day interval. Also, the trials effect $[F(2,68)=$ $91.7]$ and the interval $\times$ trials interaction $[F(2,68)=5.5]$ were significant, whereas the liquid $\times$ trials interaction $[F(2,68)=1.8]$ and the interval $\times$ liquid $\times$ trials interaction $[F(2,68)=2.7]$ were not significant. As expected, denatonium consumption increased across tests as the aversion was extinguished. Additionally, the significant interval $x$ trials interaction probably reflects the mean denatonium intakes on Test Days 2 and 3 for the 1-day groups. Their pooled denatonium consumption peaked on Test Day $2(18.8 \mathrm{ml})$ and decreased on the third test $(17.1 \mathrm{ml})$. This apparently reflects a ceiling effect. Conversely, the 5-day groups increased their denatonium consumption on each test day: Test Day $1=4.5 \mathrm{ml}$, Test Day $2=11.65 \mathrm{ml}$, and Test Day $3=15.2 \mathrm{ml}$. In summary, the one-bottle method was able to detect betweengroup differences that were due to both overshadowing and retention interval effects.

\section{Two-Bottle Groups}

The groups' mean denatonium intake and mean percentage of denatonium consumed for each of the test days are presented in Table 1. None of the groups consumed a substantial amount of denatonium. To facilitate the detection of differences with the two-bottle method, two analyses were performed, one on the groups' denatonium intakes, and the other on the percentage of denatonium consumed.

The ANOVA conducted with the denatonium intakes did not reveal any significant effects or interactions: interval $[F(1,35)<1]$, liquid $[F(1,35)=1.2]$, interval $\times$ liquid $[F(1,35)=2.8]$, trials $[F(2,70)=1.5]$, interval $\times$ trials $[F(2,70)<1]$, liquid $\times$ trials $[F(2,70)=2.7]$, and interval $\times$ liquid $\times$ trials $[F(2,70)<1]$.

The analysis of the percentage of denatonium consumed yielded similar results. No significant effects were found for any of the factors or their interactions: interval $[F(1,35)<1]$, liquid $[F(1,35)=1.1]$, interval $\times$ liquid $[F(1,35)=2.3]$, trials $[F(2,70)<1]$, interval $\times$ trials $[F(2,70)<1]$, liquid $\times$ trials $[F(2,70)=2.4]$, and interval $\times$ liquid $\times$ trials $[F(2,70)<1]$. It is clear from these results that the two-bottle testing method was inadequate for detecting reliable overshadowing or retention interval effects. 


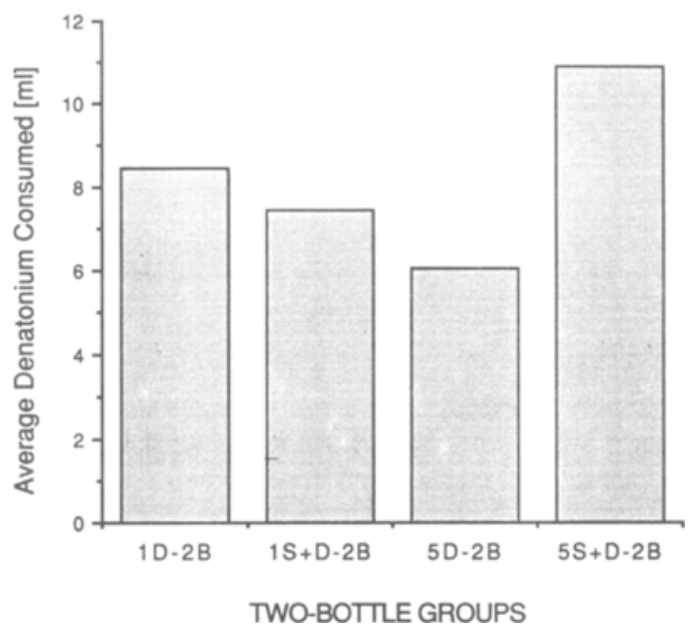

Figure 2. Mean denatonium consumption in milliliters of Groups 1D-2B, 1S + D-2B, 5D-2B, and 5S +D-2B averaged over Test Days 4 and 5 using a one-bottle test. Groups 1D-2B and 5D-2B were conditioned to denatonium whereas Groups $1 S+D-2 B$ and $5 S+D-2 B$ were conditioned to a saccharin/denatonium mixture.

As a means of detecting latent differences in aversion strength, two additional one-bottle tests were conducted with the four two-bottle groups. On Test Day 4, Group 5D-2B drank the least $(3.2 \mathrm{ml})$, Group $5 \mathrm{~S}+\mathrm{D}-2 \mathrm{~B}$ drank the most $(6.5 \mathrm{ml})$, and the two 1-day groups drank comparable amounts: Group 1D-2B $=5.3 \mathrm{ml}$, and Group $1 \mathrm{~S}+\mathrm{D}-2 \mathrm{~B}=$ $4.3 \mathrm{ml}$. On Test Day 5, a similar pattern of results was obtained: Group 5D-2B $=8.9 \mathrm{ml}$, Group 5S +D-2B $=$ $15.3 \mathrm{ml}$; Group 1D-2B $=11.6 \mathrm{ml}$, and Group $1 \mathrm{~S}+\mathrm{D}-2 \mathrm{~B}=$ $10.6 \mathrm{ml}$. The mean denatonium intakes averaged over Test Days 4 and 5 are presented in Figure 2 .

The $2 \times 2 \times 2$ ANOVA revealed a significant interval $\times$ liquid interaction $[F(1,35)=4.2]$, and a significant trials effect $[F(1,35)=120.6]$. No other effects or interactions surpassed the significance criterion: interval $[F(1,35)<$ 1], liquid $[F(1,35)=1.9]$, interval $\times$ trials $[F(1,35)<$ 1], liquid $\times$ trials $[F(1,35)=1.6]$, and interval $\times$ liquid $\times$ trials $[F(1,35)=1.6]$. Planned comparisons revealed significant overshadowing at the 5-day retention interval. No other between-group comparisons were statistically significant.

It is evident that, although the two-bottle testing method obscured detection of overshadowing at the 5-day interval over Test Days 1-3, it was present when a one-bottle testing method was employed on Test Days 4 and 5 . On the other hand, the inability to detect retention interval differences is not unexpected. Although the animals' denatonium aversions had not completely been extinguished on Test Days 4-5, these tests were performed 4 and 5 days after the 1-day groups were conditioned. Thus, retention interval effects that may have been detected on the earlier tests were difficult to detect.

\section{DISCUSSION}

With the one-bottle testing method significant overshadowing and retention interval effects were detected. Denatonium aversions following compound conditioning were significantly weaker than those of denatonium-only controls at both retention intervals. Additionally, groups conditioned to denatonium or the saccharin/denatonium mixture at a 5-day retention interval drank significantly less denatonium during testing than did their conditioning counterparts tested at a 1-day interval. Similarly conditioned groups assessed with a denatonium versus water two-bottle testing method demonstrated neither the compound conditioning effect nor the retention interval effect. These results are of methodological importance in suggesting that, although the two-bottle testing method may be a more sensitive measure for detecting weak aversions (e.g., Dragoin et al., 1971; Elkins, 1973; Grote \& Brown, 1971; Klein et al., 1975; Riley \& Mastropaolo, 1989), the one-bottle technique is superior in the detection of differential aversions.

When the two-bottle testing method was utilized, all animals avoided the aversive denatonium and almost exclusively consumed water. In fact, no changes were observed over the 3 days of testing. If testing with the two-bottle method had continued, it is possible that a significant overshadowing result might have been obtained; however, as demonstrated by Tests 4-5, any retention interval effects would have dissipated by this time. As such, the two-bottle method was clearly inadequate in detecting differences between groups that possessed strong aversions.

Although this experiment did not specifically address the mechanisms underlying retention interval effects, various aspects of these results are noteworthy. The results of the one-bottle groups are consistent with earlier reports that testing taste aversions $24 \mathrm{~h}$ after conditioning produces a weaker aversion than does testing at longer retention intervals. Batsell and Best (1992b) demonstrated that both single- and compound-element taste aversions are stronger at 21-day intervals than at 1-day intervals. The present results show that both denatonium and overshadowed denatonium aversions are stronger at a 5-day retention interval than at a 1 -day interval. This result further suggests that the differences observed between short and intermediate or long retention intervals are due to factors operating at the short retention interval.

Previous explanations for the retention interval effect have centered on the contribution of environmental cues. A retrieval competition interpretation posits that associations between the environment and the unconditioned stimulus are competing with associations between the taste and the unconditioned stimulus at the short retention intervals. As the retention interval increases, exposure to the environment also increases, and the competition provided by the association between the environment and the unconditioned stimulus is extinguished. On the other hand, 
a nonassociative account of the retention effects is also plausible. In the 24-h period following aversive conditioning, the various effects of this novel illness episode may dishabituate the environment so that performance of the taste aversion decreases (for a more extensive review, see Batsell \& Best, 1992b). Because this phenomenon requires the measurement of differential aversions, the present results indicate that a one-bottle method is preferable in the investigation of the mechanism of these retention interval effects.

In conclusion, the present experiment demonstrated that significant overshadowing and retention interval effects were more easily detected with a one-bottle testing method. These effects were obscured when a two-bottle testing method was employed. The present results suggest that researchers should match their testing technique to their experimental procedures. When the primary focus is merely on the detection of an aversion, two-bottle tests are the most sensitive. However, when differential aversions between groups is the primary concern, one-bottle tests are clearly more sensitive.

\section{REFERENCES}

BATSELL, W. R., JR., \& BEST, M. R. (1992a). Investigation of replacement fluids and retention-interval effects in taste-aversion learning. Bulletin of the Psychonomic Society, 30, 414-416

BATSELL, W. R., JR., \& BEST, M. R. (1992b). Variations in the retention of taste aversions: Evidence for retrieval competition. Animal Learning \& Behavior, 20, 146-159.

Bouton, M. E., \& Whiting, M. R. (1982). Simultaneous odor-taste and taste-taste compounds in poison-avoidance learning. Learning \& Motivation, 13, 472-494.

Bowman, M. T., Batsell, W. R., JR., \& Best, M. R. (1992). Evidence that stimulus generalization does not determine taste-mediated odor potentiation. Bulletin of the Psychonomic Society, 30, 241-243.

Davis, S. F., Best, M. R., \& Grover, C. A. (1988). Toxicosismediated potentiation in a taste/taste compound: Evidence for withincompound associations. Learning \& Motivation, 19, 183-205.

Dragoin, W., McCleary, G. E., \& McCleary, P. (1971). A comparison of two methods of measuring conditioned taste aversions. Behavior Research Methods \& Instrumentation, 3, 309-310.

ElKINS, R. L. (1973). Individual differences in bait shyness: Effects of drug dose and measurement technique. Psychological Record, 23, 349-358.

Grote, F. W., JR., \& Brown, R. T. (1971). Conditioned taste aversions: Two-stimulus tests are more sensitive than one-stimulus tests. Behavior Research Methods \& Instrumentation, 3, 311-312.

Harriman, A. E., Nance, D. M., \& Milner, J. S. (1968). Discrimination between equimolar $\mathrm{NaCl}$ and $\mathrm{LiCl}$ solutions by anosmic, adrenalectomized rats. Physiology \& Behavior, 3, 887-889.

Klein, S. B., Domato, G. C., Hallstead, C., Stephens, I, \& MikulKa, P. J. (1975). Acquisition of a conditioned aversion as a function of age and measurement technique. Physiological Psychology, 3, 379-384.

Kraemer, P. J., Lariviere, N. A., Spear, N. E. (1988). Expression of a taste aversion conditioned with an odor-taste compound: Overshadowing is relatively weak in weanlings and decreases over a retention interval in adults. Animal Learning \& Behavior, 16, 164-168.

LoLordo, V. M., Droungas, A. (1989). Selective associations and adaptive specializations: Taste aversions and phobias. In S. B. Klein \& R. R. Mowrer (Eds.), Contemporary learning theories: Instrumental conditioning theory and the impact of biological constraints on learning (pp. 145-180). Hillsdale, NJ: Erlbaum.

Miller, J. S., Jagielo, J. A., \&PEAR, N. E. (1990). Changes in the retrievability of associations to elements of the compound CS determine the expression of overshadowing. Animal Leaming \& Behavior, 18, 157-161.

Riley, A. L., \& Mastropaolo, J. P. (1989). Long-delay taste aversion learning: Effects of repeated trials and two-bottle testing conditions. Bulletin of the Psychonomic Society, 27, 145-148.

RozIN, P. (1969). Central or peripheral mediation of learning with long CS-US intervals in the feeding system? Journal of Comparative \& Physiological Psychology, 67, 421-429.

Strom, C., Lingenfelter, A., \& Brody, J. F. (1970). Discrimination of lithium and sodium chloride solutions by rats. Psychonomic Science, 18, 290-291.

Westbrook, R. F., Homewood, J., Horn, K., Clarke, J. C. (1983). Flavour-odour compound conditioning: Odour-potentiation and flavour-attenuation. Quarterly Journal of Experimental Psychology, 35B, 13-33.

\section{NOTE}

1. Although differences in conditioning fluid intake were recorded, they were not expected to contribute to differences in testing method, overshadowing, or retention interval effects. Most importantly, the differences in fluid consumption were observed across the testing measures (i.e., Groups 1D-1B [7.7 ml] and 1D-2B [7.65 ml] drank similar amounts). As such, they would not differentially favor either testing method. Second, differences between denatonium and saccharin + denatonium consumption during conditioning were not unexpected. These differences have been previously observed in this design (Batsell \& Best, 1992b), and they do not differentially favor the occurrence of overshadowing. A final concern is whether the conditioning-day intake of the 1-day animals was substantially less than the $8 \mathrm{ml}$ of water provided to their 5-day counterparts. Although slight differences in fluid deprivation may exist between these groups, the amount of fluid consumed during the 24-h period prior to testing does not mediate retention interval differences. In a recent report, Batsell and Best (1992a) have demonstrated that providing replacement fluids during the 24-h conditioningto-testing interval (i.e., elevating the animal's fluid intake to baseline amounts prior to testing) does not eliminate the differences between groups tested 1 or 5 days after conditioning. As a result, the differences in conditioning-day intake could not by themselves produce the present pattern of test-day results.

(Manuscript received January 31, 1992; revision accepted for publication July 13, 1992.) 